\title{
AVALIAÇÃO DOS RISCOS OCUPACIONAIS DE TRABALHADORES DE SERVIÇOS DE RADIOLOGIA*
}

\author{
Geraldo Sérgio Fernandes ${ }^{1}$, Antonio Carlos Pires Carvalho ${ }^{2}$, Ana Cecília Pedrosa de Azevedo ${ }^{3}$
}

Resumo OBJETIVO: Avaliar as condições de biossegurança e de trabalho de profissionais de serviços de radiologia e tecer recomendações sobre as modificações necessárias, a fim de adequar os serviços às normas vigentes no país. MATERIAIS E MÉTODOS: Foram feitas entrevistas com funcionários e observadas as seguintes atividades, executadas pelos técnicos em radiologia ou enfermeiras no local de trabalho: processo de revelação de radiografias dentro das câmaras escuras; tempo médio de permanência dos funcionários nas câmaras escuras; preparação de soluções de fixador e revelador para o processamento radiográfico e tipo de ajuda prestada aos pacientes durante os exames de raios $X$. Foi avaliada a eficiência do sistema de ventilação de duas câmaras escuras. Foram medidas as alturas das bancadas das câmaras escuras para verificar suas posições e adequação ergonômica. Quanto aos aspectos de segurança elétrica e contra incêndio, foram avaliados o número e a localização de extintores para verificar se estavam de acordo com as normas legais, e a condição de aterramento dos equipamentos elétricos. RESULTADOS: 0 sistema de ventilação era insuficiente, os profissionais não utilizavam equipamentos de proteção individual no preparo dos produtos químicos, os aspectos ergonômicos estavam em desacordo com as recomendações nacionais e os funcionários apresentam estresse relacionado ao trabalho. CONCLUSÃO: Com base nessas verificações, foram elaborados mapas de risco, para cada setor do serviço de radiologia, que servem para tomadas de decisão quanto a melhorias no ambiente.

Unitermos: Ergonomia; Mapas de risco; Biossegurança; Estresse; Equipamentos de proteção individual.

Abstract Evaluation of occupational risks among workers in radiology departments.

OBJECTIVE: To evaluate the biosafety aspects and the working conditions of radiology department professionals and to make recommendations with respect to necessary modifications to be implemented in these departments in order to comply with national regulations. MATERIALS AND METHODS: Interviews with the professionals were carried out as well as observation of their activities in the working premises including processing of radiographic films inside the dark rooms, average time inside the dark rooms, preparation of chemical solutions for automatic processors and the type of help given to patients during radiographic examinations. The efficiency of the exhausting systems in the dark rooms was also measured. The ergonomic adequacy of the accessories inside the dark rooms was analyzed. With respect to electrical safety, the location and number of fire extinguishers as well as the grounding of the electrical equipment was evaluated to check if they were in accordance with the Brazilian legislation. RESULTS: The exhaustion systems were insufficient, professionals did not wear protective clothes/devices when preparing the chemical solutions, the ergonomic aspects were not in accordance with national recommendations, and the workers presented related stress. CONCLUSION: Based on these results, risk maps were drawn for each sector of the radiology department to be used in the implementation of improvements in each sector.

Key words: Ergonomics; Biosafety; Map risks; Stress; Protective devices.

\section{INTRODUÇÃO}

O cenário atual em hospitais, clínicas e assemelhados mostra que, apesar dos esforços em investimento para o aprimoramento de profissionais, processos e equipamentos, pouco tem sido feito para pre-

* Trabalho realizado no Departamento de Radiologia da Faculdade de Medicina da Universidade Federal do Rio de Janeiro (UFRJ), Rio de Janeiro, RJ.

1. Aluno do Programa de Pós-graduação em Radiologia (Mestrado) da Faculdade de Medicina da UFRJ.

2. Professor Adjunto Doutor do Departamento de Radiologia da Faculdade de Medicina da UFRJ.

3. Física da Faculdade de Medicina da UFRJ, Pesquisadora da Fundação Oswaldo Cruz, Escola Nacional de Saúde Pública venir o surgimento de lesões e enfermidades ocupacionais e de impactos ambientais também causadores de doenças ou outros danos. Em tais locais de trabalho são encontrados diversos tipos de $\operatorname{riscos}^{(\mathbf{1})}$, que podem ser classificados como: desprezíveis, marginais, críticos ou catastróficos.

Sérgio Arouca - Centro de Estudos da Saúde do Trabalhador e Ecologia Humana (CESTEH).

Endereço para correspondência: Dra. Ana Cecília Pedrosa de Azevedo. Fundação Oswaldo Cruz, Escola Nacional de Saúde Pública Sérgio Arouca - CESTEH. Rua Leopoldo Bulhões, 1480, Manguinhos. Rio de Janeiro, RJ, 21041-210. E-mail: acpa@ensp.fiocruz.br

Recebido para publicação em 30/7/2004. Aceito, após revisão, em 14/12/2004.
No serviço de diagnóstico por imagem, um dos mais importantes instrumentos de apoio a inúmeras áreas da medicina, são observados atos inseguros e condições ambientais de insegurança, dentre eles: preparação e manuseio de soluções tóxicas sem utilização de equipamento de proteção individual (EPI); ajuda a pacientes deficientes com doenças contagiosas sem utilização de EPI; trabalhadores em ambientes onde há insalubridade resultante da presença de agentes químicos tóxicos fora dos limites estabelecidos por lei; trabalhadores e pacientes em ambientes onde há periculosidade, resultante da detecção de 
níveis de radiações ionizantes acima dos limites estabelecidos por lei; trabalhadores em ambientes com ventilação inadequada; aspectos ergonômicos em postos de trabalho em desacordo com as normas regulamentadoras; equipamentos defeituosos ou mal calibrados em operação, com conseqüentes riscos a trabalhadores e pacientes; salas com móveis, equipamentos e acessórios localizados inconvenientemente à segurança do trabalhador e à sua satisfação para realização de tarefas.

Todos esses aspectos estão relacionados à biossegurança ${ }^{(2,3)}$, que é o conjunto de ações voltadas para a prevenção, minimização ou eliminação de riscos inerentes às atividades de pesquisas, produção, ensino, desenvolvimento tecnológico e prestação de serviços, tendo por finalidade a saúde do homem e dos animais, a preservação do meio ambiente e a qualidade dos resultados ${ }^{(4)}$.

Este trabalho tem o objetivo de fazer um levantamento das condições de trabalho de profissionais de serviços de radiologia e tecer recomendações sobre as modificações necessárias de ser introduzidas nesses serviços, a fim de adequá-los às normas vigentes no país ${ }^{(\mathbf{5}, \mathbf{6})}$

\section{MATERIAIS E MÉTODOS}

Para a elaboração de recomendações sobre biossegurança aplicáveis a um serviço de radiologia, foram realizadas as seguintes atividades em um hospital público de grande porte da cidade do Rio de Janeiro: entrevistas com funcionários, com o objetivo de reunir o maior número possível de informações pessoais, dos processos desenvolvidos e dos pacientes atendidos; análise de todas as salas que compõem o serviço de radiologia e diagnóstico por imagem nos aspectos relacionados ao sistema de ventilação local, à disposição dos móveis e equipamentos, à quantidade de extintores e suas distribuições e ao aterramento dos equipamentos elétricos.

Foram observadas as seguintes atividades, executadas pelos técnicos em radiologia ou enfermeiras no local de trabalho: processo de revelação de radiografias dentro das câmaras escuras; tempo médio de permanência dos funcionários nas câmaras escuras; preparação de soluções de fixador e revelador para o processamento radiográfico e tipo de ajuda prestada aos pacientes durante os exames de raios-X.

Foi avaliada a eficiência do sistema de ventilação de duas câmaras escuras, A e B. Com a utilização de um anemômetro digital marca Minipa modelo MDA-10, foram realizadas medições para determinar a velocidade média do fluxo de ar junto da entrada do duto do ventilador, bem como a $4 \mathrm{~cm}$ desse ponto. A vazão correspondente é o produto dessa velocidade pela área da seção perpendicular do duto.

Quanto aos aspectos ergonômicos, foram medidas as alturas das bancadas das câmaras escuras, a fim de verificar suas posições e adequação ergonômica ${ }^{(7,8)}$.

Quanto aos aspectos de segurança contra incêndio, foram avaliados a localização e o número de extintores para verificar se estão de acordo com as normas do Corpo de Bombeiros.

No tocante à segurança elétrica, foi verificada a condição de aterramento dos equipamentos elétricos em uso no serviço.

No que se refere à saúde do trabalhador, foi registrado o tempo de permanência dos funcionários dentro das câmaras escuras durante o período de revelação dos filmes radiográficos.

Com base nessas verificações, foram elaborados mapas de risco para cada setor do serviço de radiologia. Este tipo de mapa é um instrumento da segurança do trabalho e da saúde ocupacional, sendo constituído de uma planta baixa do local, apresentando todos seus equipamentos, móveis e espaços de trabalho e circulação, com uma descrição simbólica dos riscos ali existentes. Ele serve para tomadas de decisão quanto a melhorias no ambiente.

\section{RESULTADOS}

Durante o período de observações dentro das câmaras escuras, foi constatado que o técnico exerce suas funções num ambiente sem renovação adequada do ar, pois o sistema de ventilação é insuficiente. A associação americana American Society of Heating, Refrigerating and AirConditioning Engineers (ASHRAE) recomenda que haja de 20 a 30 trocas de volume de ar da câmara escura por hora. Nossa avaliação demonstrou que a vazão efetiva de exaustão que o ventilador proporciona na câmara escura A é de $97 \mathrm{~m}^{3} / \mathrm{h}$ e na câmara escura B é de $268 \mathrm{~m}^{3} / \mathrm{h}$, o que representa apenas cerca de $40 \%$ da vazão mínima necessária para proporcionar 30 trocas de ar por hora. As vazões efetivas realizadas nas câmaras escuras A e B pelos exaustores são, respectivamente, de 97 $\mathrm{m}^{3} / \mathrm{h}$ e $268 \mathrm{~m}^{3} / \mathrm{h}$. Com base na recomendação da ASHRAE para as câmaras escuras mencionadas, os sistemas de exaustão dos gases tóxicos devem ser trocados por outros cujas características são: câmara escura $A=243 \mathrm{~m}^{3} / \mathrm{h}$ e câmara escura $\mathrm{B}=$ $650 \mathrm{~m}^{3} / \mathrm{h}$. Outra razão que faz com que o ambiente no interior das câmaras escuras se torne inadequado é o fato delas serem estanques quando em operação, sem nenhuma admissão de ar rico em oxigênio. Passam, então, a existir duas fontes de poluição: uma é a própria processadora e a outra é a presença do funcionário, que em seu processo de respiração absorve o oxigênio do ar após inspirá-lo e elimina o gás carbônico durante a expiração. Este problema pode ser solucionado com a instalação de uma rede de dutos individuais em cada câmara escura com seção quadrangular de $250 \mathrm{~mm} \times 250 \mathrm{~mm}$. Este sistema admitirá ar externo para o seu interior face à depressão gerada pelos ventiladores acima mencionados.

Os funcionários executam, na câmara escura, etapas relativas ao processo de revelação de radiografias que incluem a preparação de soluções de fixador e de revelador, sem utilização de EPI: luvas, avental e máscara. Com exceção dos aventais com chumbo, que são usados pelos profissionais durante os exames de raios-X e tomografia computadorizada, outros EPI não são usados na execução de tarefas. Isto contraria os Artigos 157 e 158 da Lei 6514 de 22/12/1977 e o Artigo 19 da Lei 8213 de 24/7/1991, que estabelecem que "A empresa é obrigada a fornecer aos empregados, gratuitamente, EPI adequado ao risco, em perfeito estado de conservação e funcionamento, sempre que as medidas de ordem geral não ofereçam completa proteção contra os riscos de acidentes do trabalho ou de doenças profissionais e de trabalho ...".

Considerando as atividades exercidas, são recomendados os seguintes EPI: 
- Agentes químicos (durante a preparação de soluções): luvas, máscaras e aventais de látex nitrílico.

- Agentes físicos (durante os exames em que o profissional de radiologia ajuda o paciente): anteparos de vidro plumbífero que possam ser mantidos suspensos à altura da cabeça e do pescoço do profissional durante os exames.

- Agentes biológicos (durante os exames em que o profissional de radiologia ajuda o paciente): máscaras próprias para retenção de impurezas menores do que $5 \mu$.

Os funcionários realizam exames de raios-X e tomografia computadorizada e auxiliam os pacientes durante a realização desses exames. Neste aspecto, constatouse que aproximadamente $80 \%$ das crianças atendidas são neuropatas e algumas necessitam de ajuda para que permaneçam bem posicionadas durante os exames. A quantidade média de situações em que o profissional se mantém junto ao paciente é de quatro exames por dia. Nesses momentos o funcionário fica mais exposto à radiação ionizante. A utilização do avental com chumbo não é suficiente para protegê-lo totalmente.

Quanto aos fatores ergonômicos, as câmaras escuras e a câmara clara possuem bancadas de trabalho fixadas nas paredes com alturas de $1,12 \mathrm{~m}, 1,24 \mathrm{~m}$ e 1,25 m. Contrariando as normas vigentes, as alturas das bancadas existentes nas câmaras claras e escuras (A e B) são inconvenientes como postos de trabalhos e poderão ser causa de dores lombares, dorsais, nos ombros e no pescoço, podendo gerar, a longo prazo, deformações da coluna vertebral e problemas articulares. A altura recomendada para as bancadas é entre $0,90 \mathrm{~m} \mathrm{e}$ $0,99 \mathrm{~m}$, tendo esse valor sido fruto de criterioso estudo baseado na altura dos pro- fissionais (1,62 $\mathrm{m}$ a 1,78 $\mathrm{m}$ ) e em literatura especializada $^{(7,8)}$.

Não existiam extintores com dióxido de carbono $\left(\mathrm{CO}_{2}\right)$ nas salas de exames de raios-X onde estão localizados equipamentos elétricos. $\mathrm{O}$ extintor mais próximo encontrava-se a $16 \mathrm{~m}$ de distância. Essa distância contraria a norma que estabelece em 10 m o máximo a ser percorrido num eventual incêndio. Assim sendo, é recomendada a instalação de outros extintores, a fim de que as normas de segurança sejam obedecidas.

Conforme os mapas de riscos elaborados, existem no setor os seguintes agentes: riscos físicos (elétrico e radiação); riscos químicos; riscos biológicos; riscos ergonômicos; riscos de incêndio e fatores psicossociais. Este último agente é considerado um dos principais causadores de acidentes de trabalho ou doenças ocupacionais, pois ele propicia maior exposição aos demais e coopera com o não cumprimento das regras básicas de segurança.

O lidar com a doença e a morte sempre foi para homem, mesmo que seja o profissional da saúde, um fator gerador de conflito psicológico. Foi constatado que os profissionais são afetados por esse agente devido às características do público-alvo já mencionadas e, ainda, considerando que tais pacientes quase sempre são pertencentes a famílias de baixa renda e, em alguns casos, também a lares desfeitos.

Aproximadamente $50 \%$ das crianças atendidas são portadores de HIV ou de doenças pulmonares contagiosas. Conforme já mencionado, os profissionais da radiologia permanecem junto de alguns pacientes numa média quatro exames por dia. Nesses casos, os esforços que exercem para carregar sobre si um avental de chumbo pesando $3,5 \mathrm{~kg}$ e para manter uma criança agitada na posição ideal para a tomada radiográfica proporcionam um aumento do estresse e uma elevação do risco de contaminação biológica.

\section{CONCLUSÕES}

A análise das atividades, dos procedimentos e do ambiente de trabalho no serviço de radiologia revelou a existência de agente psicossocial que prejudica emocionalmente os profissionais, tornando-os menos capazes de cumprir seu trabalho.

Com base nos resultados apresentados, foi possível concluir que, das irregularidades detectadas, a maioria apresenta soluções factíveis de serem implantadas nos serviços de radiologia, tendo em vista a disponibilidade, no Brasil, dos materiais, equipamentos e mão-de-obra capacitada necessários para sua implantação. Além disso, é inquestionável o balanço positivo da análise custo-benefício em prol de uma melhoria das condições de trabalho dos trabalhadores de serviços de radiologia.

\section{REFERÊNCIAS}

1. Brasil FS. Gerência de riscos / APR - análise preliminar de riscos. Rio de Janeiro: Ed. Funcefet, 2002.

2. Costa MAF. Qualidade em biossegurança. Rio de Janeiro: Ed. Qualitymark, 2000.

3. Teixeira P, Valle S. Biossegurança: uma abordagem multidisciplinar. Rio de Janeiro: Ed. Fiocruz, 1996.

4. Carvalho ABM. Integração de sistemas - foco na qualidade, meio ambiente, saúde e segurança. Banas Ambiental 2000;dez:46-52.

5. Brasil. Conselho Nacional do Meio Ambiente Conama. Resolução no 001 de 23 de janeiro de 1986.

6. Machado PAL. Direito ambiental brasileiro. $5^{\mathrm{a}} \mathrm{ed}$ São Paulo: Malheiros, 1995.

7. Santos PJP. Ergonomia. Rio de Janeiro: Ed. Funcefet - Cefet/RJ, 2002.

8. Woodson WE, Conover DW. Guide d'ergonomie - adaptation de la machine à l'homme. Paris: Les Éditions d'Organization, 1978 